\title{
Assessing the performance and cost-competitiveness of a dual- source solar assisted heat pump in cold climates
}

\author{
Jeremy Sager*, and Jean-Philippe Poirier \\ CanmetENERGY-Ottawa, 1 Haanel Dr., K1A 1M1, Ottawa, Canada
}

\begin{abstract}
In many cold climates, the coincidence of long heating seasons as well as relatively high levels of solar insolation offer an opportunity to explore the potential for solar-assisted air source heat pumps to meet greenhouse gas reduction objectives for space and water heating systems. This paper presents the results of a detailed performance analysis based on 6 months of field test data of a pre-commercial, dual source solar-assisted heat pump. The data gathered during field-testing as well as the functionality of the system were studied extensively to develop and calibrate an hourly energy model. The model replicates the performance and operating modes of the solar-assisted air source heat pump. It allows for an hourly assessment of the energy savings, greenhouse gas reduction potential and cost competitiveness of this system as compared to other high performance HVAC systems in a variety of climate locations and archetype house loads. A parametric analysis is undertaken to assess the impact of key components on system viability. Results indicate that for some regions and archetype house loads, the dual-source solar-assisted heat pump can lead to significant energy savings and GHG emissions reductions when compared to high performing HVAC systems. These savings may enable a favorable payback period when a competitive capital cost is considered. The objective of the study was to identify locations and archetypes in which this solar-assisted heat pump topology may make sense for further development and demonstration.
\end{abstract}

\section{Introduction}

In cold climates with access to low-greenhouse gas (GHG) emitting sources of electricity generation such as Canada's, electrification of space heating is seen as a key element in meeting climate change goals. In the near term in Canada, cold-climate air source heat pumps (CC-ASHP) are poised to take up this challenge. However, in the longer-term, solutions will need to maximize the use of renewable sources of energy. In many cold-climate regions, such as some regions in Canada, the coincidence of long heating seasons as well as high levels of solar insolation offer an opportunity to explore the potential for solar-assisted heat pumps (SAHP). These systems may be viewed as an alternative to ground-source heat pumps for applications in which disturbing the ground is not feasible or not costeffective.

The work presented herein evaluates the operating cost and greenhouse gas (GHG) emissions savings of one SAHP topology when compared with CC-ASHPs in Canada. The evaluation was done using a tool developed at CanmetENERGY-Ottawa (CE-O) called "the Housing HVAC System Comparative Analysis Tool" or "HVAC Tool" as it will be referred to herein. A SAHP model was implemented in the HVAC Tool based on field testing data as a source for performance and operational characteristics.

\section{Housing HVAC System Comparative Analysis Tool}

The HVAC Tool allows for the comparative analysis of HVAC systems in an Excel-based calculation spreadsheet. The user creates a model of the system to be analyzed and uses the Tool's preloaded load, weather, GHG emissions and utility cost files to compare the performance of the system being modeled to base case systems. The spreadsheet incorporates space heating, cooling and hot water loads for three archetype homes for a wide range of cities across Canada. The load and weather data is all pre-calculated (external to the spreadsheet) using NRCan's Housing Technology Assessment Platform (HTAP). The HTAP software suite can be obtained directly from Natural Resources Canada. [1] HTAP is a collection of data and tools that automate and extend the HOT2000 residential energy simulation tool from a monthly resolution to hourly resolution. [2] HOT2000 has been extensively used for energy rating, code compliance, and incentive programs in the Canadian housing sector. [3] Utility costs are taken from across Canada as of September 2020 and include the effects on fuel prices of a $\$ 30 /$ tonne carbon levy. [4]

\footnotetext{
*Corresponding author: jeremy.sager@canada.ca
} 


\section{Testing at the Canadian Centre for Housing Technology}

The Canadian Centre for Housing Technology (CCHT) is a facility located in Ottawa, Canada, used for evaluating whole-house performance of residential technologies. [5] A pre-commercial prototype dualsource SAHP was installed and tested at the CCHT InfoCentre building as shown in Figure 1 below. The system was available in Europe for some time (circa 2013) but had never been tested in North America or in climatic conditions comparable to those in Ottawa.

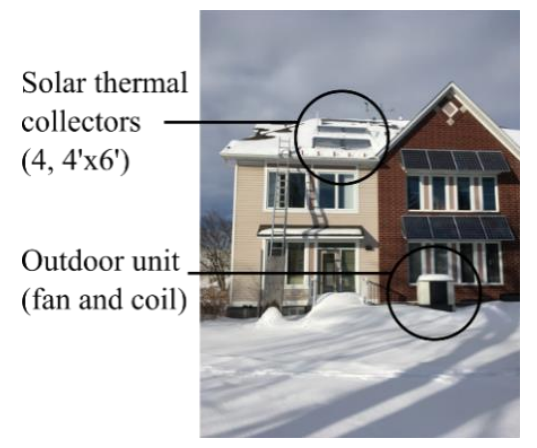

Figure 1. CCHT InfoCentre SAHP equipment outside

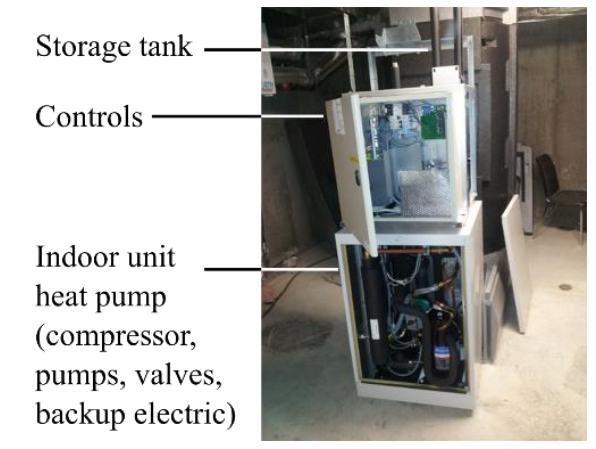

Figure 2. CCHT InfoCentre SAHP equipment inside

\subsection{Installation, operation, instrumentation and data collection}

The existing heating system in the building was monitored for a period of 1 month in the winter heating season (February to March 2015), during which design heating temperatures for Ottawa were reached $\left(-25^{\circ} \mathrm{C}\right)$. The design heat loss was calculated to be $6.4 \mathrm{~kW}$ at $25^{\circ} \mathrm{C}$. The system selected had an EN 14511 maximum rated capacity at the $\mathrm{A} 7 / \mathrm{W} 35$ test condition of $6.2 \mathrm{~kW}$.

Four solar thermal collectors were roof mounted facing due south. An outdoor unit with fan and heat exchanger were installed on a stand above the snow level, also on the south side of the InfoCentre. The indoor unit contained the controls, single-stage scroll compressor, liquid-to-liquid heat exchangers, and two variable speed pumps circulating a glycol-water working fluid. One pump circulated the working fluid from the heat pump evaporator to the outdoor unit and a second pump circulated the fluid through the solar collectors. The third variable speed pump circulated water from the heat pump condenser to the air-handler unit (AHU) or storage tank. Backup heat was provided to the AHU or storage tank via an inline electric waterheating element rated at 3-9 $\mathrm{kW}$. In the glycol-water evaporator loop, a three-way valve controlled the flow from the heat pump to the outdoor unit and/or solar thermal collectors as a source of heat (thus the "dualsource" classification of the system). In the waterside condenser loop, a three-way valve controlled the flow from the heat pump to the storage tank or the AHU. Heat was distributed to the building via a hydronic air handler (not shown) running on continuous low speed air circulation (resulting in an average of $3-5^{\circ} \mathrm{C}$ temperature difference across the coil of the AHU). An outdoor temperature sensor was installed and connected to the system controller. Domestic hot water (DHW) was provided by a freshwater module that isolated the waterside of the system from the potable waterside.

The system was instrumented such that all source and sink liquid loop flowrates were measured for each operating loop in the system. Inlet and outlet temperatures for each loop were also measured. Mass flow and capacity of each loop could therefore be calculated independently. Energy consumption of each pump, valve and the controller were also independently monitored. Data was gathered at a 1-minute timestep for a period of approximately 6 months from December 16, 2017 to June 16, 2018.

\section{Dual-source solar assisted heat pump model}

The dual-source SAHP working model diagram is shown in Figure 3 and the engineering schematic is presented in Figure 4. The system, as modelled, consists of a storage tank, solar thermal collectors, a heat pump, and auxiliary heating elements. To account for storage tank stratification, a two-node approach was adopted. The two nodes are linked together by volume, the sum of which makes up the total tank volume. The nodes are characterised by a uniform temperature calculated at each timestep. Operational modes determine the temperature and the volume of water that are transferred from the bottom "cold" node to the top "hot" node, hereafter referred to as Node 2 and Node 1 respectively.

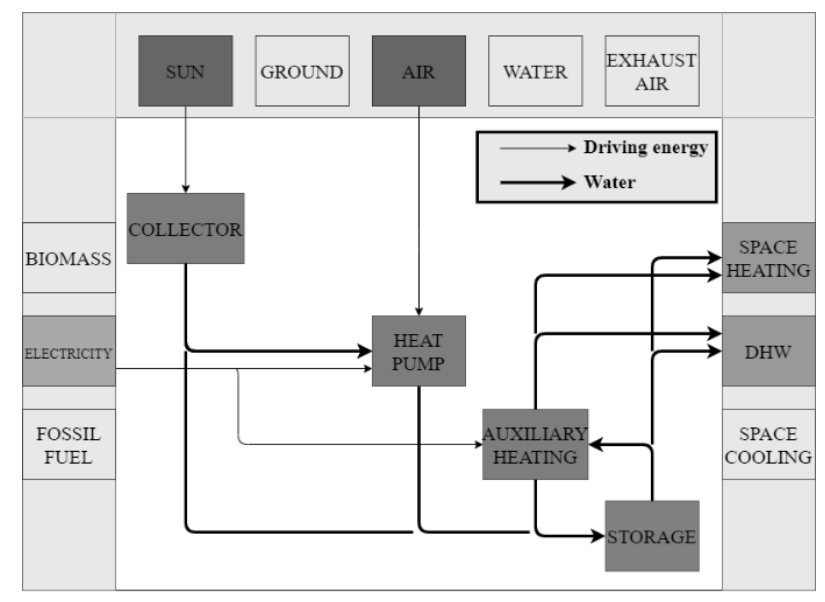

Figure 3. Dual-source SAHP working model diagram 
The SAHP model has four operational modes, according to the system as tested at the CCHT:

(1) Solar only mode

(2) Heat pump only mode

(3) Solar boost mode

(4) Auxiliary heating mode

The first two modes represent a parallel SAHP topology in which both modes can operate independently. Solar boost mode represents the system operating in series where energy from the collectors is used to increase the heat pump's capacity.

At the start of each timestep, water is drawn from Node 1 to meet the space heating and DHW loads. Following these draws, the state of the tank determines whether one or more modes need to be activated to charge the tank. Each mode is therefore defined by a control logic (described below).

The space-heating load was met by circulating water through a hydronic AHU, which would return water to Node 2 at the indoor thermostat set point. The DHW load was met by drawing a volume of water from Node 1 and supplying Node 2 with the same volume of water but at mains temperature.

Three pumps were used to model the circulation of water through the system. The first pump supplied water to the outdoor unit from the heat pump evaporator. The second pump supplied water from the storage tank to the collectors and the third pump supplied water to the AHU through the heat pump condenser and auxiliary heating element.

\subsection{Solar only mode}

Solar only mode used the collectors to heat water from Node 2 and circulate it to Node 1. The available solar energy was calculated by using the hourly solar irradiance HTAP data for each region. The solar energy collected was then calculated by multiplying the collector efficiency by the panel surface area and the available solar energy. The collector tilt was adjusted to respect a site latitude $+10^{\circ}$ angle to maximise the amount of energy collected in space heating.

The dual-source SAHP system can be implemented with one or two sets of four collectors depending on the requirements of the installation. Each set of 4 collectors were arranged in parallel to maintain the same tank inlet temperature.

The volumetric flow rate through the collectors was based on the CCHT testing data and was determined by the available solar irradiance at each timestep with a maximum flow rate of $0.48 \mathrm{~m}^{3} / \mathrm{h}$. The flow rate would increase proportionally to the number of collectors.

The solar pump power consumption was $40 \mathrm{~W}$ for 4 collectors and $80 \mathrm{~W}$ for 8 collectors, based on measured pump power use obtained during CCHT testing.

\subsubsection{Solar only mode control logic}

Solar only mode was activated when there was solar energy available, and the tank was not fully charged. The availability of solar energy was determined based on the temperature of Node 2, the solar irradiance at the corresponding timestep, and the collector efficiency. The tank was defined as fully charged when it reached a maximum temperature of $95^{\circ} \mathrm{C}$. Solar only mode could not be activated in instances where Solar boost mode was enabled. This assumed the mixing valve would thereby fully open or fully close depending on the mode.

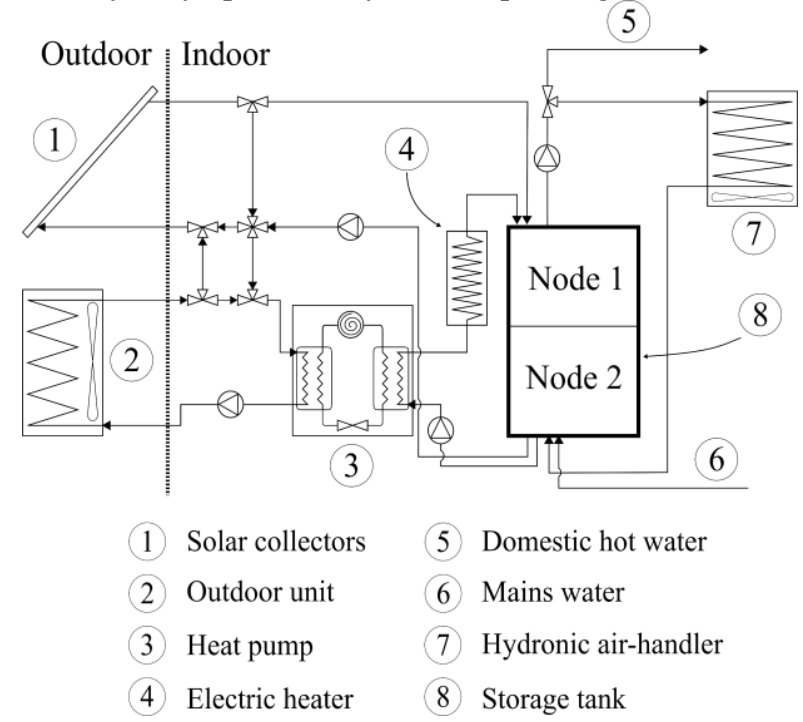

Figure 4. Dual-source SAHP model engineering schematic

\subsection{Heat pump only mode}

Heat pump only mode would heat water from Node 2 through the heat pump's condenser, which would then be returned at Node 1 . Water in a separate closed loop was circulated from an air-to-water outdoor unit to the heat pump's evaporator. The performance of the heat pump as defined by the capacity, coefficient of performance (COP), and volumetric flow rate was determined using data collected at the CCHT and was dependent on outdoor ambient temperature.

The power consumption of the heat pump unit was determined by the COP and capacity whereas the power consumption of the outdoor unit fan and associated pumps was set to $350 \mathrm{~W}$, as measured during CCHT testing.

\subsubsection{Heat pump only mode control logic}

Heat pump only mode was activated under the following conditions:

(1) Node 1's temperature was lower than the hot water temperature set point of $55^{\circ} \mathrm{C}$.

(2) There was no solar energy available.

(3) Node 1's volume made up less than half the storage tank's volume.

Furthermore, the outdoor unit had an operational low temperature limit of $-16^{\circ} \mathrm{C}$. The heat pump condenser was limited by a maximum inlet temperature of $45^{\circ} \mathrm{C}$, and a maximum outlet temperature of $65^{\circ} \mathrm{C}$. During testing at the CCHT, the system would rarely exceed these temperatures, which indicated the presence of an operational ceiling associated with the $\mathrm{R} 407 \mathrm{c}$ refrigerant used in the heat pump. 


\subsection{Solar boost mode}

Solar boost mode enabled the collectors and heat pump to operate in series when conditions were favourable (see section 4.3.1). The performance of solar boost mode was defined by COP and capacity and was dependent on available solar energy. Solar boost mode's COP increase was linear relative to heat pump only mode up to solar irradiance levels of $250 \mathrm{~W} / \mathrm{m}^{2}$. When solar irradiance levels were above this threshold, solar boost mode was multiplied by a factor dependent on solar irradiance. Solar boost mode's capacity was determined by multiplying the heat pump's capacity by a factor calculated based on solar irradiance. This approach was determined by analyzing performance data collected at CCHT during solar boost mode as a function of heat pump only mode.

Solar boost mode's volumetric flow rate was equal to the heat pump's flow rate since they used the same pump to circulate water from the storage tank to the condenser. When solar boost mode was active, the solar pump, outdoor unit pump and indoor unit pump consumed a total of $200 \mathrm{~W}$. Solar boost mode did not activate the outdoor unit fan, which means it consumed less power than the heat pump only mode.

\subsubsection{Solar boost mode control logic}

Solar boost mode was enabled when there was solar energy to be collected as defined in section 4.1 and the heat pump was activated at the same time.

\subsection{Auxiliary heat mode}

Auxiliary heat mode activated an electric resistance heater to heat the water in instances where the other modes were not available or when the water being delivered to the AHU or the DHW freshwater module from Node 1 was lower than their respective set points of $40^{\circ} \mathrm{C}$ and $55^{\circ} \mathrm{C}$. The auxiliary heat mode was also modelled as being capable of charging the tank when the other modes were not available by heating water from Node 2 and returning it to Node 1 at the hot water temperature set point.

When the Auxiliary heat mode tops up the tank, it activated a pump that consumed $30 \mathrm{~W}$, as measured during testing at the CCHT.

The volumetric flow rate was determined with the same data used to calculate the heat pump's condenser flow rate since both modes used the same circulator pump as shown in Figure 4.

\subsubsection{Auxiliary heat mode control logic}

Auxiliary heat mode was enabled when the outdoor ambient temperature was below the heat pump's operating temperature of $-16^{\circ} \mathrm{C}$ and when Node 1 was below the hot water temperature set point.

Only one auxiliary heating element was available to the system, which meant that when it was used to increase the temperature for a space heating or DHW draw, it could not also be used to top up the tank in the same timestep.

\subsection{Model deviations from the CCHT field tested system}

A few key simplifications were implemented in the model to avoid the intricacies of the field-tested system. They include:

(1) The storage tank was assumed to be open, meaning all operating modes circulated the same working fluid.

(2) The working fluid was assumed to be water throughout the system whereas the field-tested system circulated a water/glycol mixture in the outdoor unit and solar collector loops.

(3) Heat exchanger effectiveness was assumed to be $100 \%$.

(4) All inlet and outlet ports were modelled as being at the top and bottom of the storage tank whereas the field-tested system could draw and circulate water from multiple points along the storage tank's height.

\subsection{Model parameters}

\subsubsection{SAHP model}

The SAHP model was parameterised to meet the space and DHW heating loads for each city and archetype combination. The capacity increments available in the model were selected based on the precommercial prototype system options from the manufacturer, as presented in Table 1.

Table 1. SAHP system sizing options

\begin{tabular}{|l|c|c|c|}
\cline { 2 - 4 } \multicolumn{1}{c|}{} & System 1 & System 2 & System 3 \\
\hline $\begin{array}{l}\text { Heat pump capacity } \\
{[\mathrm{kW}]}\end{array}$ & 6.2 & 8.3 & 11.1 \\
\hline $\begin{array}{l}\text { Auxiliary heater size } \\
{[\mathrm{kW}]}\end{array}$ & $3 / 6 / 9$ & $3 / 6 / 9 / 12$ & $3 / 6 / 9 / 12 / 15$ \\
\hline $\begin{array}{l}\text { Solar collector surface } \\
\text { area }\left[\mathrm{m}^{2}\right]\end{array}$ & $10-20$ \\
\hline $\begin{array}{l}\text { Storage tank volume } \\
{\left[\mathrm{m}^{3}\right]}\end{array}$ & \multicolumn{3}{|c|}{0.94} \\
\hline
\end{tabular}

\subsubsection{Base case CC-ASHP model}

The CC-ASHP model was sized according to the space-heating load of the archetype and city combination. Three CC-ASHP options were available for the comparative analysis and each unit was characterised by a performance map with capacity and efficiency based on outdoor ambient temperature as shown in Figure 5. Space heating loads where outdoor temperatures were below the rated operational minimum of the CC-ASHP were met by electric resistance heating at $100 \%$ efficiency. Each CC-ASHP performance map defined the maximum and minimum capacity and COP of the system. Loads above maximum capacity were assumed to be met with electric resistance heating, while 
loads below the minimum capacity were assumed to be met at the minimum capacity COP (i.e., the performance degradation due to cycling was not accounted for). Note that the performance map data used for the base case commercially available, market-leading CC-ASHP was obtained from data tables as tested to CSA C656 / AHRI 240 for a market-leading commercially available system, and as such defrost energy consumption is not included.

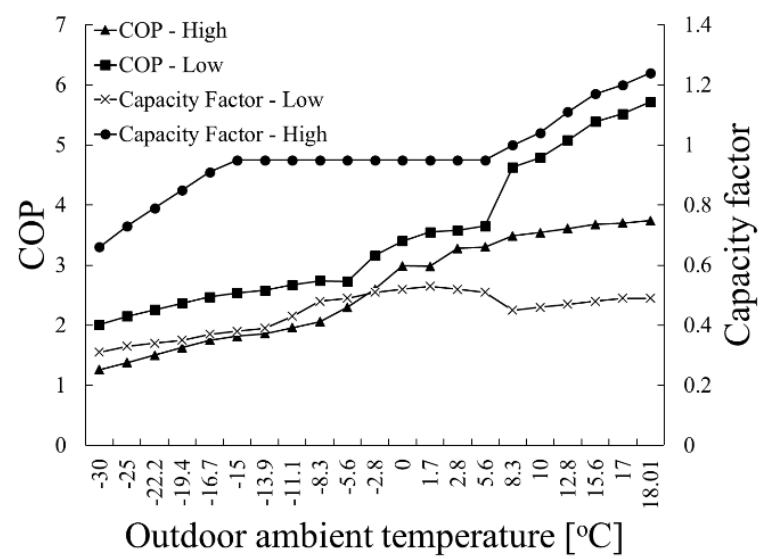

Figure 5. CC-ASHP performance map for System 2

The CC-ASHP was modelled as a space-heating only unit; therefore, the DHW load was met by electric resistance heating.

Table 2. CC-ASHP system sizing options

\begin{tabular}{|l|c|c|c|}
\cline { 2 - 4 } \multicolumn{1}{c|}{} & System 1 & System 2 & System 3 \\
\hline $\begin{array}{l}\text { Heat pump } \\
\text { capacity }[\mathrm{kW}]\end{array}$ & 9.86 & 11.6 & 15.66 \\
\hline
\end{tabular}

\section{Results}

\subsection{Model validation}

Testing at the CCHT lasted for 3401 hours between December 2017 and June 2018. Since the model is based on yearly average weather data, validation required adjusting the weather data in the model to more closely match the weather experienced during the field test. Montreal, the nearest available city in the model to the field test location, was used for this purpose. The model was validated by comparing the testing data and the modelling results for the same number of hours over the same months.

When comparing ambient temperature data between the field measured data and model, as shown in Figure 6 , a $2.75^{\circ} \mathrm{C}$ average temperature difference was observed. The model ambient temperature data was therefore reduced for the testing period to bring it in line with the temperature trends observed in the field data. Similarly, the solar irradiance measured during testing was $26 \%$ lower on average than the solar irradiance model data. The modelling data for solar irradiance was therefore also modified to validate the results.

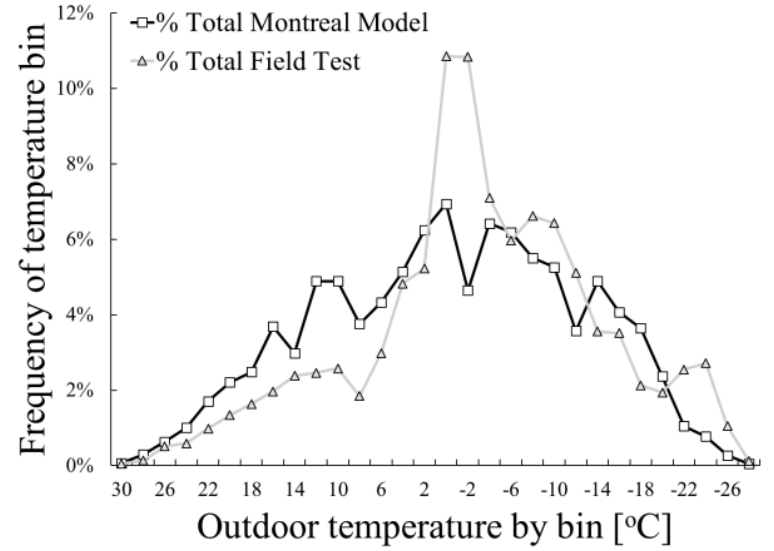

Figure 6. Outdoor temperature bins for field test and Montreal model

Figure 7 presents the results for the system energy output and energy input for three archetype house loads in Montreal when compared with testing data from the CCHT for the duration of field testing. The plotted results present a linear relationship between the energy input and energy output of the SAHP, which indicates the model is in line with the CCHT field test data.

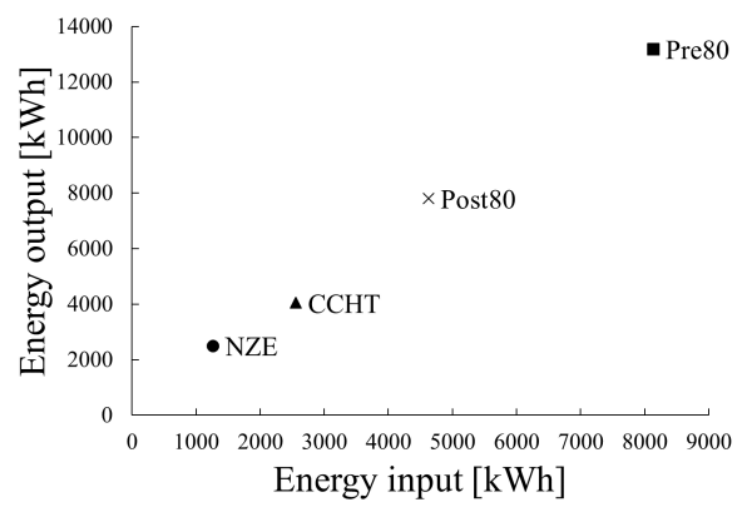

Figure 7. SAHP energy output and energy input for the CCHT and HVAC tool archetypes (Montreal) for 3401 hours as tested

The energy input was divided into three main categories to observe whether each mode was being fractioned proportionally in the model. The three main consumers of electrical energy were the auxiliary heater, the heat pump compressor, and the circulation pumps \& fan.

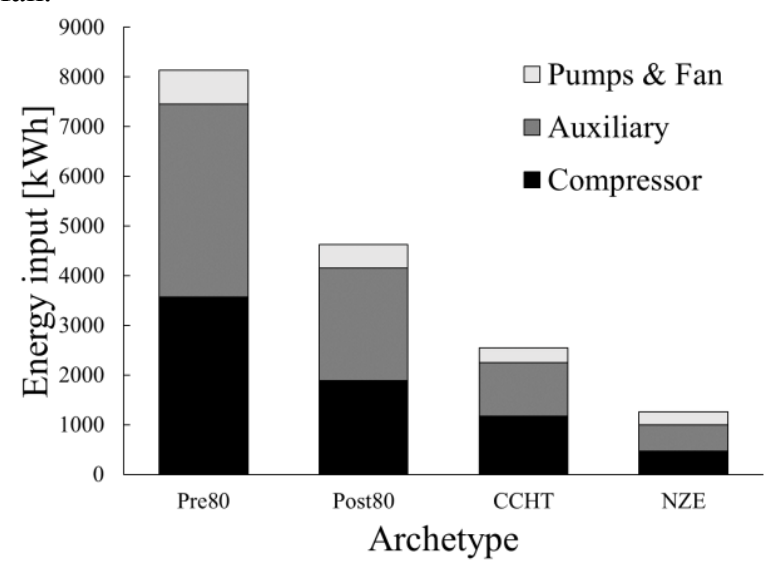

Figure 8. Energy input by archetype for model validation 
In Figure 8, we can observe a proportional decrease in energy input for each component as the design load decreases, bringing the total energy input in line with the measured energy input at the CCHT.

\subsection{HVAC tool comparative analysis results}

The five cities chosen to conduct the comparative analysis were Winnipeg, Vancouver, Calgary, Montreal, and Toronto. Three archetypes were modelled for each city: a pre-1980s home (Pre80), a post-1980s home (Post80), and a net-zero energy home (NZE), whose load lines were defined by the HTAP data. The CCASHP was chosen as the base case system due to it being viewed within Canada as a market leader for the next generation of electrically powered heating equipment.

The modelled configurations for each city are presented in Tables 3 through 7. The SAHP's heat pump capacity and auxiliary heater were increased until the archetype heating load could be met.

Table 3. Heating energy use and system sizing for Winnipeg

\begin{tabular}{|l|c|c|c|}
\cline { 2 - 4 } \multicolumn{1}{c|}{} & Pre80 & Post80 & NZE \\
\hline $\begin{array}{l}\text { Heating energy use } \\
\text { [kWh/year] }\end{array}$ & 38783 & 19985 & 7034 \\
\hline $\begin{array}{l}\text { SAHP heat pump / } \\
\text { auxiliary capacity (kW) }\end{array}$ & $11.1 / 15$ & $8.3 / 12$ & $6.2 / 6$ \\
\hline $\begin{array}{l}\text { CC-ASHP heat pump / } \\
\text { auxiliary capacity (kW) }\end{array}$ & $\begin{array}{c}15.66 / \\
13\end{array}$ & $15.66 / 5$ & $11.6 / 0.5$ \\
\hline
\end{tabular}

Table 4. Heating energy use and system sizing for Vancouver

\begin{tabular}{|l|c|c|c|}
\cline { 2 - 4 } \multicolumn{1}{c|}{} & Pre80 & Post80 & NZE \\
\hline $\begin{array}{l}\text { Heating energy use } \\
\text { [kWh/year] }\end{array}$ & 17402 & 8772 & 3130 \\
\hline $\begin{array}{l}\text { SAHP heat pump / } \\
\text { auxiliary capacity (kW) }\end{array}$ & $6.2 / 3$ & $6.2 / 3$ & $6.2 / 3$ \\
\hline $\begin{array}{l}\text { CC-ASHP heat pump / } \\
\text { auxiliary capacity (kW) }\end{array}$ & $9.86 / 0$ & $9.86 / 0$ & $9.86 / 0$ \\
\hline
\end{tabular}

Table 5. Heating energy use and system sizing for Calgary

\begin{tabular}{|l|c|c|c|}
\cline { 2 - 4 } \multicolumn{1}{c|}{} & Pre80 & Post80 & NZE \\
\hline $\begin{array}{l}\text { Heating energy use } \\
\text { [kWh/year] }\end{array}$ & 31284 & 16062 & 5246 \\
\hline $\begin{array}{l}\text { SAHP heat pump / } \\
\text { auxiliary capacity (kW) }\end{array}$ & $11.1 / 15$ & $8.3 / 9$ & $6.2 / 6$ \\
\hline $\begin{array}{l}\text { CC-ASHP heat pump / } \\
\text { auxiliary capacity (kW) }\end{array}$ & $15.66 / 9$ & $11.6 / 2.5$ & $11.6 / 0$ \\
\hline
\end{tabular}

Table 6. Heating energy use and system sizing for Montreal

\begin{tabular}{|l|c|c|c|}
\cline { 2 - 4 } \multicolumn{1}{c|}{} & Pre80 & Post80 & NZE \\
\hline $\begin{array}{l}\text { Heating energy use } \\
\text { [kWh/year] }\end{array}$ & 28642 & 14545 & 4940 \\
\hline $\begin{array}{l}\text { SAHP heat pump / } \\
\text { auxiliary capacity (kW) }\end{array}$ & $11.1 / 15$ & $6.2 / 9$ & $6.2 / 3$ \\
\hline $\begin{array}{l}\text { CC-ASHP heat pump / } \\
\text { auxiliary capacity (kW) }\end{array}$ & $15.66 / 6$ & $9.86 / 0$ & $9.86 / 0$ \\
\hline
\end{tabular}

Table 7. Heating energy use and system sizing for Toronto

\begin{tabular}{|l|c|c|c|}
\cline { 2 - 4 } \multicolumn{1}{c|}{} & Pre80 & Post80 & NZE \\
\hline $\begin{array}{l}\text { Heating energy use } \\
\text { [kWh/year] }\end{array}$ & 25393 & 12761 & 4308 \\
\hline $\begin{array}{l}\text { SAHP heat pump / } \\
\text { auxiliary capacity (kW) }\end{array}$ & $8.3 / 12$ & $6.2 / 6$ & $6.2 / 3$ \\
\hline $\begin{array}{l}\text { CC-ASHP heat pump / } \\
\text { auxiliary capacity (kW) }\end{array}$ & $11.6 / 2$ & $9.86 / 0$ & $9.86 / 0$ \\
\hline
\end{tabular}

\subsubsection{Operating cost and GHG emission savings}

The operating cost and GHG emissions savings of the SAHP are calculated relative to the CC-ASHP for 10 and $20 \mathrm{~m}^{2}$ of collector surface area. The capital cost of the SAHP (being a non-commercial system) is difficult to ascertain, and the capital cost of the CC-ASHP varies widely across markets in Canada. For these reasons, the operating cost savings are presented as a 20 -year total for the SAHP versus the CC-ASHP. The 20-year total savings serves as a target for how much higher the capital cost of the SAHP could be over the CC-ASHP and still result in a payback over its 20 -year equipment lifetime.

Figure 9 presents the results for Winnipeg, which is characterised by high space-heating loads (5600 heating degree-days, HDD) and low solar irradiance, averaging $264 \mathrm{~W} / \mathrm{m}^{2}$. The SAHP shows no savings relative to a CC-ASHP for the Pre80 archetype with either 10 or 20 $\mathrm{m}^{2}$ of collector area. Operating cost savings are possible, however, in Post80 and NZE archetype homes with their reduced space-heating loads being the primary cause of the savings. To limit the SAHP from using auxiliary electric heat in instances of high space-heating loads, a larger storage tank could be used. The effect of doubling the size of the storage tank from $0.94 \mathrm{~m}^{3}$ to $1.88 \mathrm{~m}^{3}$ is also presented in Figure 9 for the Pre 80 archetype home. The Pre 80 archetype home benefits the most from the added storage tank volume to better cope with the instances of high space-heating loads resulting in a net positive annual operating cost savings as shown. The NZE archetype, on the other hand, sees little improvement in potential operating cost and $\mathrm{GHG}$ emissions savings when increasing the storage tank volume (not shown).

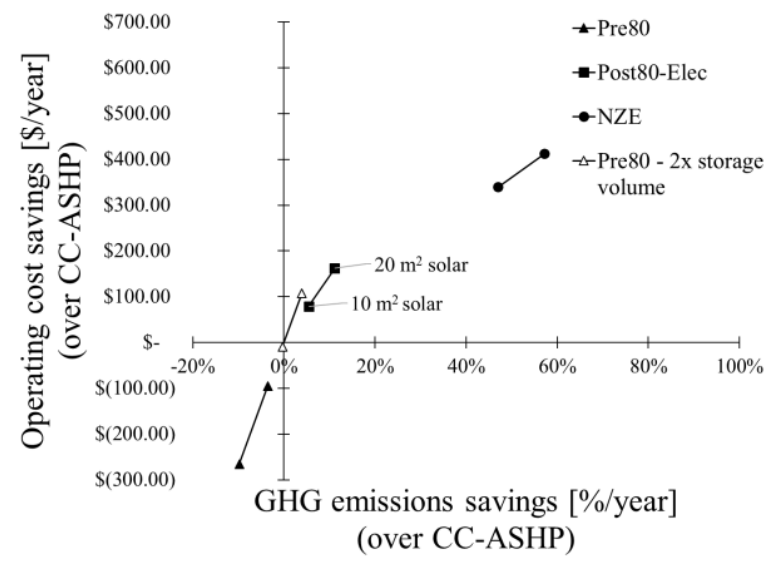

Figure 9. Operating cost and GHG emissions savings in Winnipeg

The NZE archetype shows the greatest potential in Winnipeg with GHG reductions of over $50 \%$ and operating cost savings of $\$ 6000 \mathrm{CAD}$ over the CCASHP for $10 \mathrm{~m}^{2}$ of solar collector surface area and $\$ 8000 \mathrm{CAD}$ for $20 \mathrm{~m}^{2}$ of solar.

Figure 10 presents the results for Vancouver, which is much milder than Winnipeg (2800 HDD). Vancouver has relatively low levels of solar irradiance, averaging 
$246 \mathrm{~W} / \mathrm{m}^{2}$. Operating cost savings and GHG emissions reductions are observed in all archetype homes in Vancouver. Additional solar collector surface area offers limited additional savings.

A simple payback is possible in the NZE archetype when assuming a 20-year equipment life cycle if the SAHP has an installed cost of no more than $\$ 6000 \mathrm{CAD}$ over the CC-ASHP for 10 or $20 \mathrm{~m}^{2}$ of solar. Both the Pre80 and Post80 archetype homes see limited potential for a simple payback. This makes Vancouver the least likely to benefit from a dual-source SAHP when compared with a CC-ASHP from a strictly cost savings perspective. Indeed, in Vancouver with its $-7^{\circ} \mathrm{C}$ design heating temperature, a lower cost non-cold-climate ASHP could be most cost effective. However, from a GHG emissions reductions perspective, the SAHP can result in substantial GHG savings in both the Post80 and NZE archetypes of $30-40 \%$ and $75-80 \%$ respectively.

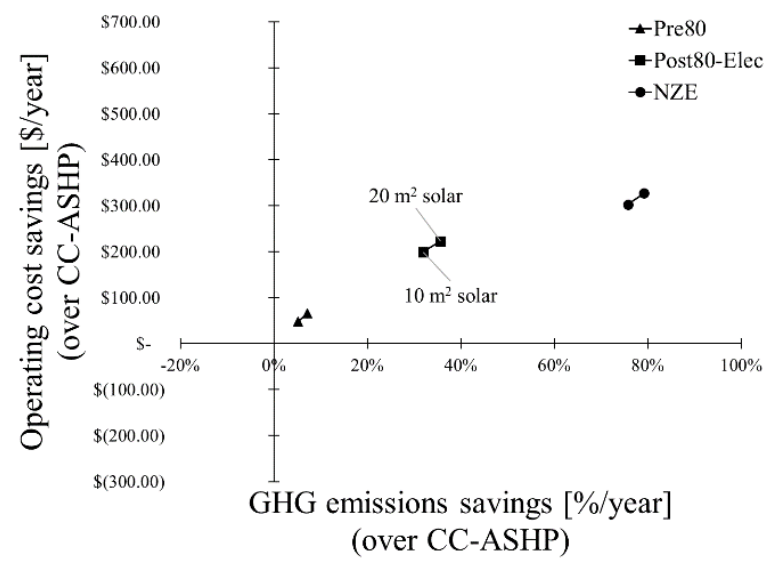

Figure 10. Operating cost and GHG emissions savings in Vancouver

Figure 11 presents the results for Calgary, a high space-heating load (5000 HDD) and high solar irradiance city, averaging $314 \mathrm{~W} / \mathrm{m}^{2}$. This city demonstrates significant operating cost and GHG emissions savings. A simple payback is possible in the NZE and Post 80 archetypes when assuming a 20-year equipment life cycle if the SAHP has an installed cost of no more than $\$ 6,000 \mathrm{CAD}$ and $\$ 10,500 \mathrm{CAD}$ over the CC-ASHP for 10 or $20 \mathrm{~m}^{2}$ of solar respectively.

Calgary is also characterised by high electrical grid GHG emissions, which means savings enabled by added renewables are more pronounced as compared to some other jurisdictions in Canada. The dual-source SAHP can reduce 27 tonnes of $\mathrm{CO}_{2}$-equivalent over the assumed 20-year equipment life cycle for the Post 80 archetype home, and 54 tonnes of $\mathrm{CO}_{2}$-equivalent for the NZE archetype home.

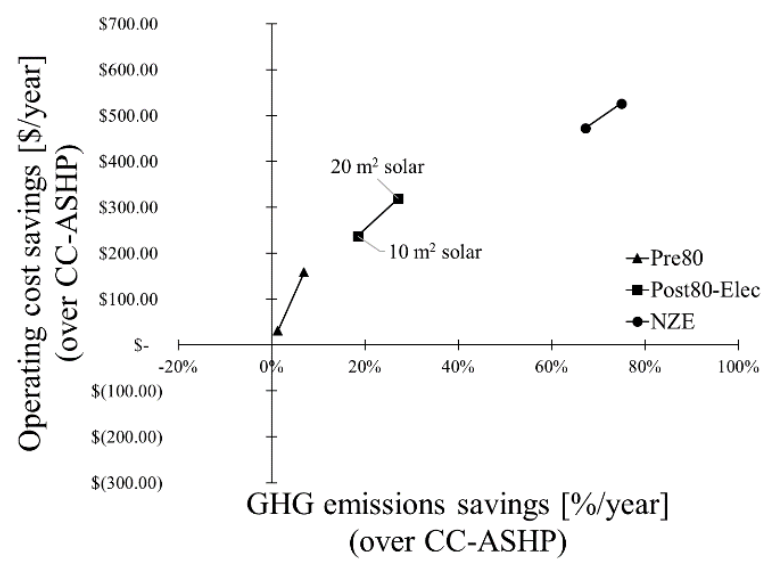

Figure 11. Operating cost and GHG emissions savings in Calgary

Figure 12 presents the results for Montreal, a city also characterised by high levels of average solar irradiance at $320 \mathrm{~W} / \mathrm{m}^{2}$ but with lower space heating loads (4200 HDD) than Calgary.

In Montreal, the SAHP can lead to substantial operating cost savings, albeit lower than in Calgary given Quebec's extremely low electricity rates (among the lowest in Canada). For example, in a NZE home, when assuming a 20 -year equipment life cycle, a simple payback requires the SAHP installed cost be no more than $\$ 6,000$ CAD over the CC-ASHP for $10 \mathrm{~m}^{2}$ of solar and $\$ 7,000 \mathrm{CAD}$ for $20 \mathrm{~m}^{2}$ of solar. The Pre80 and Post 80 archetypes see limited potential for a simple payback, given the low savings.

The electricity grid in Quebec currently emits much fewer GHG emissions than the electricity generation in Alberta, which means the GHG savings are less impactful when taken in absolute terms. Nevertheless, GHG emissions reductions of close to $80 \%$ are possible in Montreal with the SAHP in the NZE archetype home.

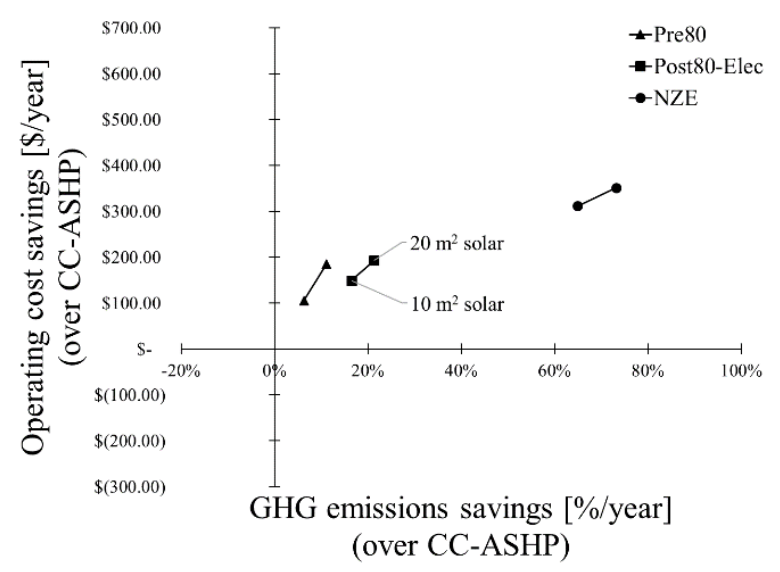

Figure 12. Operating cost and GHG emissions savings in Montreal

Lastly, Figure 13 presents the comparative analysis results for Toronto, a moderately cold city (3500 HDD) with moderate solar irradiance, averaging $265 \mathrm{~W} / \mathrm{m}^{2}$.

Toronto is located in Ontario, which has high electricity rates relative to other provinces in Canada. This combination of factors leads to high operating cost savings of 274 \$/year when compared to a CC-ASHP in 
a Pre80 archetype home. Based on a 20 -year equipment life cycle, a simple payback would be possible if the installed cost of the SAHP is no more than \$7,500 CAD over the CC-ASHP for $20 \mathrm{~m}^{2}$ of solar collector surface area. For a NZE home archetype, a simple payback would be possible with a SAHP installed cost of up to $\$ 14,000$ CAD over the CC-ASHP for $20 \mathrm{~m}^{2}$ of solar collectors, making this location and archetype case study especially favourable for the SAHP.

GHG emissions savings are also substantial in Toronto, with the NZE archetype resulting in an $80 \%$ reduction in GHG emissions when assessed using hourly emissions factors.

Toronto is in the Province of Ontario, in which the majority of residential space heating needs are met with natural gas combustion furnaces. At the same time, the electrical grid mix in Ontario uses natural gas combined cycle power plants and/or hydroelectric resources to supply the majority of its marginal electrical generation. When assessing the impacts of electrification of space heating in Toronto then, it is useful to assess GHG emissions impacts using seasonal hourly marginal emissions factors (MEF), which assumes that the CCASHP system itself adds load to the grid that would require marginal electrical generators to take up that load. Under these circumstances, and using the Post80 's archetype as an example, an additional $10 \%$ of GHG savings are observed for the SAHP versus the CCASHP.

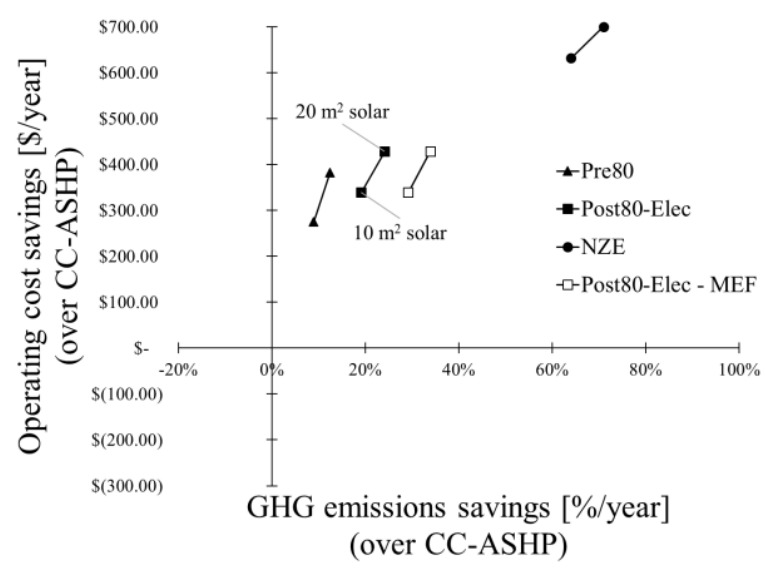

Figure 13. Operating cost and GHG emissions savings in Toronto

\section{Conclusion}

The analysis undertaken shows that the dual-source SAHP can substantially reduce GHG emissions in all but one of the archetype homes and locations assessed in Canada when compared to a high-performance CCASHP. The SAHP is particularly well suited to NZE home applications in which the domestic hot water load is the dominant load. In these homes, GHG reductions of $50-80 \%$ can be achieved along with annual utility bill savings of $\$ 300-\$ 700 \mathrm{CAD}$. This means that if the SAHP can be purchased and installed for $\$ 7,500 \mathrm{CAD}$ or less as compared to the cost of a competing CCASHP, it will have a payback period less than 20 years.
The SAHP makes the most sense economically in Calgary, Toronto, and Montreal where the coincidence of solar irradiance and heating loads favours the SAHP operating characteristics. Indeed, in a NZE home archetype in Calgary, the SAHP annual operating cost savings total $\$ 10,000 \mathrm{CAD}$ over the equipment life cycle. In Toronto, the SAHP annual operating cost savings total $\$ 14,000 \mathrm{CAD}$ over the equipment life cycle as compared to the CC-ASHP for $20 \mathrm{~m}^{2}$ of solar collectors

In terms of parametric analysis of the impact of key system components on system viability, it was found that doubling the solar collector area would be a costeffective performance improvement in regions with high electricity rates and/or regions with high solar irradiance such as Toronto and Calgary. It was also found that increasing the storage tank size would be required in the highest load case (Pre80s archetype in Winnipeg) to enable annual energy savings.

Further research will seek to perform a detailed cost analysis of the dual-source SAHP system topology to determine if the operating cost savings identified can yield a payback over the equipment lifetime versus a high performance CC-ASHP. A modelling and prototype development project is also planned to assess the feasibility of integrating a $\mathrm{CO}_{2}$ refrigerant-based heat pump into the dual source SAHP topology (which could improve cold weather performance).

\section{References}

[1] A. Ferguson, J. Blake, J. Purdy, and R. Asaee, Housing Technology Assessment Platform. GitHub: Natural Resources Canada, 2020.

[2] R. Asaee, A. Ferguson, and A. Wills, "Application of a Housing Technology Assessment Simulation Platform in Regulation R\&D," presented at the 16th Annual IBPSA International Conference, 2019.

[3] R. Asaee, "NRCan Tools for Industry Professionals (HOT2000)," Feb. 05, 2018. https://www.nrcan.gc.ca/energyefficiency/energy-efficiency-homes/professionalopportunities/tools-industry-professionals/20596.

[4] J. Sager and A. Ferguson, "Cost-Effectiveness of Cold-Climate Heat Pumps in Canadian Homes," Natural Resources Canada, 2020. Publication forthcoming.

[5] J. Sager, M. Armstrong, and F. Szadowski, "Cooling and Heating Season Performance Assessment of a Cold Climate Air Source Heat Pump at the Canadian Centre for Housing Technology," Natural Resources Canada, 2013. 